\title{
An approximate method for the design of stiffened steel compression panels
}

\author{
M. R. HORNE \& R. NARAYANAN
}

Mr D. Allen, John Sardis \& Associates, San Francisco

I have recently proposed a new design approach to buckling interaction ${ }^{10}$ which may be summarized as follows for the case of a compression panel.

37. For each element of the panel, the failure stress $\sigma_{f}$ is given by

$$
\frac{1}{\sigma_{\mathrm{f}}{ }^{n}}=\frac{1}{\sigma_{\mathrm{e}}{ }^{n}}+\frac{1}{\sigma_{\mathrm{c}}{ }^{n}}+\frac{1}{\sigma_{\mathrm{ys}}{ }^{n}} \quad . \quad . \quad . \quad . \quad . \text {. }
$$

where $\sigma_{0}$ elastic local buckling stress

$\sigma_{\theta}$ elastic overall buckling stress (Euler)

$\sigma_{\mathrm{ys}}$ yield stress

$n$ number which can account for imperfections.

38. If $\sigma_{0}$ is ignored and $n=1$, equation (10) becomes the Rankine strut formula.

39. If $\sigma_{0}$ or $\sigma_{\mathrm{e}} \geqslant 3 \sigma_{\mathrm{ys}}$, their effects may be ignored. This is equivalent to a plateau which produces a discontinuity in the curve represented by equation (10) of about $5 \%$ when $n=2$. Of course it is possible to ignore the plateau if the purist cannot accept a discontinuity.

40. The average failure stress $\sigma_{\mathrm{A}}$ is calculated from the elemental $\sigma_{\mathrm{f}}$.

41. In the case of a stiffened plate, when $\sigma_{b}<3 \sigma_{y s}$, the elastic local buckling stress $\sigma_{\mathrm{c}}$ should be used. This is to account for the fact that plate buckling can interact on the overall buckling. When $\sigma_{\mathrm{o}}>3 \sigma_{\mathrm{ys}}$, a pseudo-elastic stress $\sigma_{\mathrm{cg}}=1.5 \sqrt{ }\left(E \sigma_{\mathrm{yg}}\right) /(b / t)$ is to be used, if greater than $\sigma_{\mathrm{c}}$. This is equivalent to strengths predicted by the effective width concept which allows for additional post-buckled strength.

42. Equation (10) has been compared with test results on cold-formed columns ${ }^{11,12}$ and on a series of tests in Australia on stiffened plates ${ }^{13,14}$ with good correlation.

43. Table 3 shows the comparison of equation (10) with the test results of the Paper. In all cases the minimum yield stress of the steel specified has been used, because actual yield stresses were not published in the Paper. Some over-conservatism is to be expected in the comparison as a result.

44. By calculating the failure loads for each element, it is possible to determine a centre of failure of the whole section. This is where the external load should be applied for maximum efficiency. As the location of the applied load is not given in the Paper, no further analysis on these lines is possible. A certain degree of eccentricity is implicit in equation (10), and as the test comparison shows uniformity it is concluded that no further reduction in $\sigma_{A}$ is necessary because of the non-alignment of force axes.

45. Apart from specimen E22 which had large eccentricities, and was even underestimated by the Merrison rules, all values obtained by the proposed method are 
acceptable for design purposes (if the imperfections are not greater than those allowed by the Merrison rules). No limitation is placed on its applicability.

46. Plate $\mathrm{K}$ values have been taken in the comparison as though the common edge were simply supported. Edge fixities could easily be taken into account by elastic methods available, ${ }^{15}$ which would increase $\sigma_{c}$ slightly.

47. Reference 13 outlines the design procedure when lateral loading is present.

48. The method is simple and easily understandable, and the word effective has been eliminated. As an illustration of the method, specimens E11-23 are now analysed

$$
\begin{gathered}
\sigma_{\mathrm{ys}}=345 \mathrm{~N} / \mathrm{mm}^{2} \\
\text { area of plate }=2971 \mathrm{~mm}^{2} \\
\text { area of stiffener }=950 \mathrm{~mm}^{2} \\
r_{x} \text { of full section }=20.8 \mathrm{~mm} \\
l / r_{x}=1830 / 20 \cdot 8=88 \cdot 1 \\
\sigma_{o}=\pi^{2} E / 88 \cdot 1^{2}=261 \mathrm{~N} / \mathrm{mm}^{2} \\
\sigma_{o} / \sigma_{y s}=261 / 345=0.76<3 \\
d / t=457 / 6 \cdot 5=70 \cdot 3 \\
\sigma_{\mathrm{o}}=\frac{\pi^{2} E}{3\left(1-\nu^{2}\right)} \frac{1}{70 \cdot 3^{2}}=147 \mathrm{~N} / \mathrm{mm}^{2}
\end{gathered}
$$

\begin{tabular}{|c|c|c|c|c|c|c|c|}
\hline 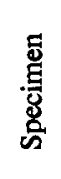 & 它递 & 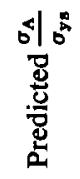 & 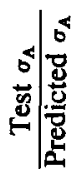 & 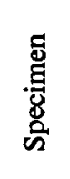 & 告范 & 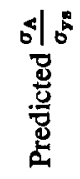 & 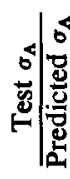 \\
\hline $\begin{array}{l}6 \\
1 \\
4 \\
2 \\
3 \\
\text { C3 } \\
\text { B11 } \\
\text { B12 } \\
\text { B21 } \\
\text { B22 }\end{array}$ & $\begin{array}{l}0.92 \\
0.87 \\
0.90 \\
0.83 \\
0.85 \\
0.77 \\
0.63 \\
0.65 \\
0.67 \\
0.62\end{array}$ & $\begin{array}{l}0.81 \\
0.81 \\
0.81 \\
0.81 \\
0.75 \\
0.76 \\
0.55 \\
0.55 \\
0.55 \\
0.55\end{array}$ & $\begin{array}{l}1 \cdot 14 \\
1.07 \\
1.11 \\
1.03 \\
1.13 \\
1.01 \\
1.15 \\
1.18 \\
1.22 \\
1.13\end{array}$ & $\begin{array}{l}\text { A11 } \\
\text { A12 } \\
\text { A21 } \\
\text { A23 } \\
\text { A22 } \\
\text { C2 } \\
\text { D11 } \\
\text { D12 } \\
\text { D21 } \\
\text { D22 }\end{array}$ & $\begin{array}{l}0.55 \\
0.56 \\
0.64 \\
0.62 \\
0.56 \\
0.87 \\
0.63 \\
0.65 \\
0.57 \\
0.60\end{array}$ & $\begin{array}{l}0.54 \\
0.54 \\
0.54 \\
0.54 \\
0.54 \\
0.74 \\
0.56 \\
0.56 \\
0.56 \\
0.56\end{array}$ & $\begin{array}{l}1.02 \\
1.04 \\
1 \cdot 19 \\
1.15 \\
1.04 \\
1 \cdot 18 \\
1.13 \\
1.16 \\
1.02 \\
1.07\end{array}$ \\
\hline $\begin{array}{l}7 \\
14 \\
12 \\
8 \\
13 \\
11\end{array}$ & $\begin{array}{l}0.79 \\
0.83 \\
0.79 \\
0.85 \\
0.75 \\
0.79\end{array}$ & $\begin{array}{l}0.80 \\
0.80 \\
0.80 \\
0.80 \\
0.80 \\
0.80\end{array}$ & $\begin{array}{l}0.99 \\
1.04 \\
0.99 \\
1.06 \\
0.94 \\
0.99\end{array}$ & $\begin{array}{l}\text { E11 } \\
\text { E12 } \\
\text { E21 } \\
\text { E23 } \\
\text { E22 }\end{array}$ & $\begin{array}{l}0.47 \\
0.48 \\
0.44 \\
0.45 \\
0.34\end{array}$ & $\begin{array}{l}0.41 \\
0.41 \\
0.41 \\
0.41 \\
0.41\end{array}$ & $\begin{array}{l}1 \cdot 15 \\
1.17 \\
1.07 \\
1 \cdot 10 \\
0.83\end{array}$ \\
\hline
\end{tabular}

Plate. As

use $\sigma_{\mathrm{o}}$ and not $\sigma_{\mathrm{cm}}$

From equation (10)

$$
\begin{gathered}
\frac{1}{\sigma_{f}^{2}}=\frac{1}{261^{2}}+\frac{1}{147^{2}}+\frac{1}{345^{2}} \\
\sigma_{\mathrm{f}}=120 \mathrm{~N} / \mathrm{mm}^{2}
\end{gathered}
$$

Table 3. Comparison of equation (10) with the test results 
Stiffener

$$
\begin{gathered}
\frac{d}{t}=\frac{76}{12 \cdot 5}=6.1 \\
\sigma_{\circ}=\frac{0.416 E}{\left(1-v^{2}\right)} \frac{1}{6 \cdot 1^{2}}=2481 \mathrm{~N} / \mathrm{mm}^{2}
\end{gathered}
$$

As this is greater than $3 \sigma_{y s}$ it may be neglected. From equation (10)

$$
\begin{gathered}
\frac{1}{\sigma_{\mathrm{f}}{ }^{2}}=\frac{1}{261^{2}}+0+\frac{1}{345^{2}} \\
\sigma_{f}=208 \mathrm{~N} / \mathrm{mm}^{2} \\
\sigma_{\mathrm{A}}=\frac{(208 \times 950)+(120 \times 2971)}{3921}=141 \mathrm{~N} / \mathrm{mm}^{2} \\
\frac{\sigma_{\mathrm{A}}}{\sigma_{\mathrm{ys}}}=\frac{141}{345}=0.41
\end{gathered}
$$

The position of the centre of failure from the centre of the plate is given by

$$
\frac{208 \times 950 \times(76+6.5) / 2}{(208 \times 950)+(120 \times 2971)}=14.7 \mathrm{~mm}
$$

whereas the centroid of the full section is at $10.0 \mathrm{~mm}$. If the load were applied at the centroid, failure in the plate rather than the stiffener would be expected.

Dr G. H. Little, University of Birmingham

The Merrison interim design rules ${ }^{2}$ for stiffened compression flanges, although an essential stop-gap measure, are now generally regarded as too complicated, and in many cases too pessimistic, to be adopted as a long-term solution. In the search for better alternative rules, my colleagues and $I^{8, \theta .16}$ have been joined by the Authors. They are to be commended for trying to ensure that their approximate method is simple to apply, and also for providing further evidence of the inaccuracy of Merrison.

50. The Authors use the common approach in which a typical single stiffener-plate unit is treated as an isolated pin-ended column. They allow for plate buckling by replacing the actual plate width $b$ by an effective width $b_{\mathrm{e}}(\leq b)$, determined only from considerations of plate strength, and assume the failure load of their effective column to be equal to that of the actual column. The basis of this procedure is the same as that implied in BS 153. There are two differences in detail: the specification of $b_{\mathrm{e}}$ and the choice of column curve. In my opinion, the Author's method is unsafe in both these respects.

51. A rigorous analysis of plate collapse is complex ${ }^{17-18}$ and the Authors simplify the problem considerably by assuming that a compression plate can sustain no increase of load beyond the point at which the longitudinal edge stress reaches yield. The earliest use of this collapse criterion, to my knowledge, was that of Davidson. ${ }^{20}$ An approximate value for this maximum load is then found from an elastic analysis of an initially stress-free, but unflat, plate. This type of approach to plate collapse has been discussed by Dawson and Walker. ${ }^{21}$ It suffers from a number of limitations as explained in \$8. The Authors (in equation (4)) propose an empirical modification to the amplitude of the initial out-of-flatness, in order to produce realistic strength predictions for welded plate elements. This important modification was proposed without evidence to verify its accuracy.

52. The resulting plate strength predictions for grade 50 steel $\left(\sigma_{\mathrm{ys}}=350 \mathrm{~N} / \mathrm{mm}^{2}\right)$ are compared with the corresponding BS 153 strength curve for welded plates in Fig. 8. The proposed curves have been calculated assuming an initial out-of-flatness $\delta_{x}$ of $b / 1000$. This value of $\delta_{\mathbf{x}} / b$ is typical of practical constructions, as has been verified ${ }^{22}$ by measurements on actual bridges using a ripple scanner. The BS 153 curve agrees well with 


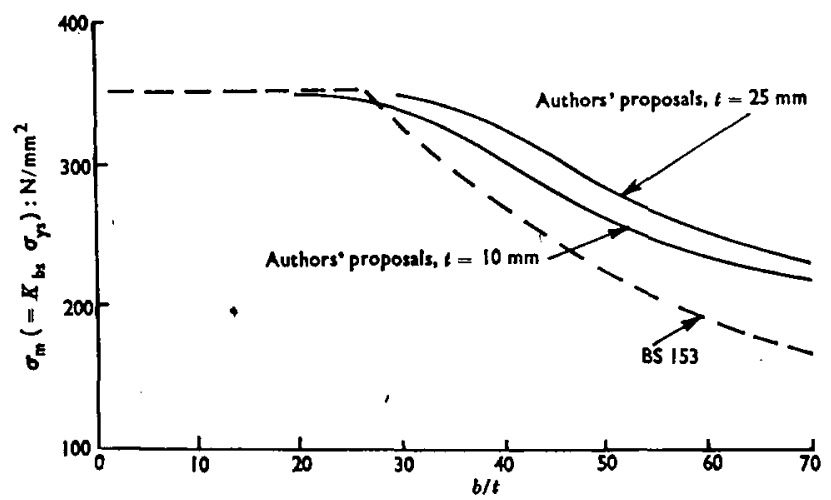

Fig. 8. Plate strength curves-comparison of Authors' proposals with BS 153 (welded plates) ; $\sigma_{\mathrm{ys}}=350 \mathrm{~N} / \mathrm{mm}^{2}, \delta_{\mathrm{x}}=b / 1000$

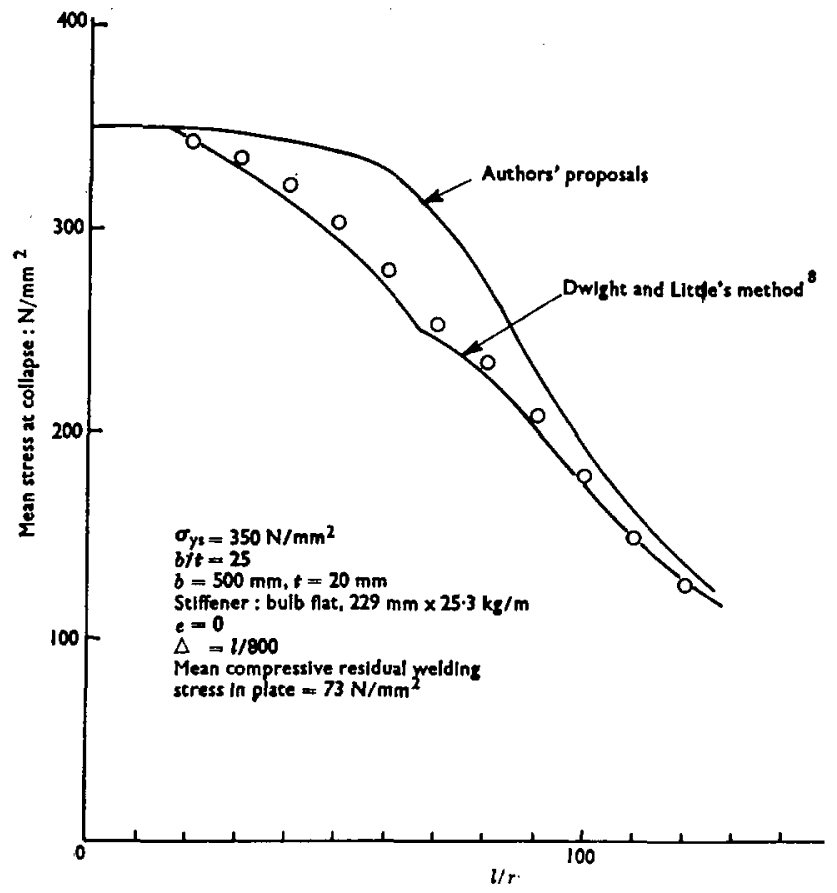

Fig. 9. Column strength curves-comparison of two design methods with accurate theory. The accurate theory ${ }^{18}$ is plotted as points (all data are based on the assumption that $b / t$ is low enough for plate buckling to be negligible, i.e. $K_{\mathrm{bs}}=1.00$ instead of 0.994 calculated from equations $(2)-(4)$ with $\delta_{x}=b / 1000$ ) 
test results for plates with welds of medium severity. ${ }^{23.24}$ Some of these test results included initial out-of-flatness measurements ${ }^{24}$ which again showed $\delta_{x} \simeq b / 1000$. The Authors' proposals (Fig. 8) appear to overestimate plate strength considerably, by more-surely-than could be attributed to the unloaded edges of the plate being maintained straight ${ }^{19}$ (a strengthening factor not allowed for in BS 153).

53. A curious property of the Authors' proposals is that, for given values of $\delta_{x} / b$ (or $\delta_{x} / t$ ), $b / t$ and $\sigma_{y \mathrm{a}}$, the predicted plate strength is a maximum at $t=25 \mathrm{~mm}$. For example, Fig. 8 shows that the strength curve for $t=10 \mathrm{~mm}$ lies well below the $t=25 \mathrm{~mm}$ curve. Is there any physical basis for this?

54. Thin compression plates can suddenly lose some stiffness before reaching their collapse load, either, at low $b / t$, by premature yielding owing to compressive residual welding stresses, or, at high $b / t$, by elastic local buckling. These stiffness drops can have a big weakening effect on stiffener-plate column strength. ${ }^{16}$ Thus it is essential to allow fully for the effect of plate stiffness, as well as plate strength, on stiffened panel strength. The Authors (\$8) recognize the need to allow for loss of plate stiffness at high $b / t$, although it seems that no allowance has actually been made. However, the plate-stiffness effect at low $b / t$ is ignored. An example of the possible dangerous consequences of this omission is given in Fig. 9, which compares the Authors' proposals with my accurately computed ${ }^{*}$ plate-failure predictions ${ }^{18}$ for typical welded stiffenerplate columns of low $b / t$ (negligible plate buckling). The accurate predictions all lie below the Authors' proposals. In the region of intermediate $L / r$ the Authors' proposals are up to $20 \%$ unsafe. The degree of unsafety increases with the level of residual welding stresses in the plate. At low $L / r$, the rapid rate of strength reduction with increasing $L / r$ is due to the reduced plate stiffness at high applied compression.

55. The design curve of method $4^{8,16}$ is also included in Fig. 9. This is a composite curve formed from two of the European column curves and lies close to the accurate theory, on the safe side. In addition, it is based on a sound physical argument ${ }^{16}$ and is simple to apply.

56. The design case where $b / t$ is low (about 20, say) has not been covered in the Authors' testing programme. Thus the inadequacy of the Authors' method to cope with this important case will not be evident from Table 2.

57. The Authors claim that method 4 is 'unreliable for shorter panels with $b / t \simeq 70$.' These specimens had stiffeners of slenderness considerably greater than the limits specified in the method. It is not surprising, therefore, that strength predictions made on the assumption that the stiffener can sustain its squash load tend to be unsafe, especially at low $L / r$. Also, it is difficult to understand why the Authors have applied their method to these specimens as they state (\$3) that stiffener outstands must be 'sufficiently stocky for there to be no danger of local stiffener failure or tripping.' Conservative strength predictions (about $10 \%$ low) can be made for these specimens using method 4 by estimating the local strength of the stiffener using the method of Rogers and Dwight. ${ }^{9,25}$

58. Most specimens tested by the Authors had stiffeners of compact section. For these, the test results are compared with the predictions of method 4 in Table 4 (column 7 of Table 2 is inaccurate, possibly because the Authors did not allow correctly for the different yield stresses in stiffener and plate). The effect of eccentric load (specimen E22) is allowed for simply by the fact that method 4 deals with mid-skin plate stresses, which can easily be converted to the corresponding centroid values. Table 4 shows method 4 to be satisfactorily accurate, its predictions generally being slightly on the safe side.

59. Do the symbols $\Delta_{x}$ and $r$ take different meanings in Tables 1 and 2 from their meanings elsewhere in the Paper?

- Equilibrium deflected shapes found by numerical integration along the column length. 
Table 4. Authors' test results compared with design rule of Dwight and Little $^{8}$ (method 4). Only those specimens with stiffeners of compact section have been included. Strength predictions correspond to the stiffened panel centroid position, and are based on the measured yield stresses of the stiffener and plate material: they replace the values given in column 7 of Table 2 . Residual stresses are allowed for using the classification given in method 4

\begin{tabular}{c|c|c}
\hline Specimen & $\begin{array}{c}\text { Observed } \\
\text { strength }\end{array}$ & $\begin{array}{c}\text { Predicted } \\
\text { strength }\end{array}$ \\
\hline 6 & 0.92 & 0.83 \\
1 & 0.87 & $0.79^{*}$ \\
4 & 0.90 & 0.87 \\
2 & 0.83 & $0.83^{*}$ \\
7 & 0.79 & $0.77^{*}$ \\
14 & 0.83 & $0.75^{*}$ \\
12 & 0.79 & 0.77 \\
8 & 0.85 & 0.80 \\
13 & 0.75 & $0.76^{*}$ \\
11 & 0.79 & 0.79 \\
D11 & 0.63 & $0.56^{*}$ \\
D12 & 0.65 & 0.63 \\
D21 & 0.57 & $0.55^{*}$ \\
D22 & 0.60 & 0.57 \\
E11 & 0.47 & $0.44^{*}$ \\
E12 & 0.48 & 0.44 \\
E21 & 0.44 & $0.42^{*}$ \\
E23 & 0.45 & 0.44 \\
E22 & 0.34 & $0.36^{*}$ \\
\hline
\end{tabular}

Mr C. D. Bradfield, University of Cambridge

The Authors obtain equation (3) by considering the stiffness of a simple elastic, initially stress-free model. The empirical equation (4) is crucial to the relation between the stiffness of the Authors' model and the strength of real plates. How did the Authors arrive at this expression, and within what limits of plate dimensions, residual stresses, initial out-of-flatnesses and yield stresses have they verified it?

61. It is surprising to see $\delta_{\mathrm{x} M}$ appearing in an expression for the strength of real plating. The definition of this quantity in $\$ 8$ implies that, for plates less than $25 \mathrm{~mm}$ thick, imperfections vary as $b / t$ (because the term in parentheses is $1.1 \pm 0.05 \mathrm{~mm}$ in practical compression plating). I have had the opportunity to study extensive surveys of bridge compression plating, concentrating on the ripple component of out-of-flatness which affects the local buckling strength. No correlation between $\delta_{\mathrm{x}}$ and $b / t$ was found. The best fit expression was to take $\delta_{x}$ directly proportional to $b$. In detail $2 / 3$ of all plates had $\delta_{x} / b$ under $0.001 ; 95 \%$ are below 0.003 (in plates fabricated before detailed inspection was required).

62. It will be necessary to select a value of $\delta_{x}$ for design. The surveys, together with the plate strength calculations of Moxham, ${ }^{17,26}$ Crisfield $^{27}$ and Frieze et al..$^{28}$ indicate that the coefficient of variation of plate strength due to varying imperfection is under $5 \%$. This is less than that due to varying yield stress, where it is already accepted that $5 \%$ of material falls below the characteristic yield stress used for design. In this situation the design imperfection should be a representative value, not an extreme value which one believes never to be exceeded. Similarly $100 \%$ inspection of plate flatness is unjustifiable. More benefit would come from tightening control on yield stresses. Detailed considerations suggest that $\delta_{\mathrm{x}}=0.001 b$ is a suitable design imperfection.

63. The Authors' interpolation between multiple column strength curves is more complex than the usage adopted for ordinary columns. For columns, three closely spaced curves are defined for each yield stress, and all column sections are assigned to one or other of the curves. Anything more elaborate is not justified because the scatter in the results of tests on similar columns is comparable to the spacing of the curves. Do the Authors consider that such a body of experimental and accurate 
theoretical work is now available on the more complex subject of stiffened plating that their more elaborate procedure can be justified?

\section{Mr P. Davies and Dr A. C. Walker, University College London}

The Authors have presented a significant contribution to the search for a simple yet adequately accurate method of design for stiffened panels. The value of the Paper is in the manner in which the Authors have used the results of their series of tests on various geometries to develop and verify their suggested method for design analysis. The method outlined deals only with one mode of panel collapse, i.e. where the stiffener is unbuckled. Could the Authors indicate at what level of negative column imperfection it is possible for the stiffener tripping mode of failing to be induced?

65. In common with other column-type approaches the Authors' method derives a value for the Perry coefficient $\eta$ based on a reduced effective width of plating, which allows for buckling of the plate element including the effect of initial deformations and residual welding stresses, and an initial deflexion of the effective column. The implicit allowance of residual welding stresses in plate strength equations has already been suggested, ${ }^{29}$ and this work has formed the basis of a paper on the design of stiffened plates. ${ }^{14}$ Table 5 compares this method with the Authors' experimental results and design analytical predictions for continuously welded plates with as-received imperfections; it also includes the corresponding theoretical values using Dwight and Little's method. ${ }^{9}$ There is variability between both the various methods and the experimental results.

66. The coefficients in each of the analytical approaches are adjusted to fit the available test results. In reference 29 the experimental work of Murray ${ }^{30}$ and Dorman and Dwight ${ }^{31}$ is shown to be in good agreement also with the analytical predictions. There is need for a rational investigation and comparison of these various approximate methods because if one is to be presented as a design method there must be certainty about the interpretation of the analysis and the range of validity of the various empirical coefficients used.

67. We feel that no design approach should be proposed on the basis of one set of experimental results only because it is possible for a systematic error to exist on any particular testing arrangement. Also, it is essential that the degree of scatter, or reproducibility, of the panel collapse loads for various geometric parameters should be investigated to determine the accuracy of the proposed design curves.

\section{Table 5}

\begin{tabular}{|c|c|c|c|c|}
\hline \multirow[t]{2}{*}{ Specimen } & \multirow{2}{*}{$\begin{array}{c}\text { Measured } \\
\text { strength }\end{array}$} & \multicolumn{3}{|c|}{ Predicted strength } \\
\hline & & $\begin{array}{l}\text { Authors' } \\
\text { approximate } \\
\text { method }\end{array}$ & $\begin{array}{c}\text { Dwight and } \\
\text { Little }^{9}\end{array}$ & $\begin{array}{c}\text { Walker and } \\
\text { Murray }^{29}\end{array}$ \\
\hline $\begin{array}{l}6 \\
\text { B22 } \\
7 \\
\text { A23 } \\
\text { A22 } \\
\text { C2 } \\
\text { D22 } \\
\text { E23 } \\
\text { E22 }\end{array}$ & $\begin{array}{l}0.92 \\
0.62 \\
0.79 \\
0.62 \\
0.56 \\
0.87 \\
0.60 \\
0.45 \\
0.34\end{array}$ & $\begin{array}{l}0.87 \\
0.68 \\
0.78 \\
0.61 \\
0.56 \\
0.79 \\
0.68 \\
0.44 \\
0.36\end{array}$ & $\begin{array}{c}0.81 \\
0.67 \\
0.81 \\
0.62 \\
-\overline{0.67} \\
0.53 \\
0.41 \\
-\end{array}$ & $\begin{array}{l}0.82 \\
0.57 \\
0.81 \\
0.56 \\
0.51 \\
0.80 \\
0.70 \\
0.49 \\
0.37\end{array}$ \\
\hline
\end{tabular}


68. Small stiffened plate panels are being manufactured by welding steel sheet and tested in the Department of Civil and Municipal Engineering at University College London. One advantage of this modelling facility is the ability to test inexpensively a number of specimens on any particular geometry. For example, six nominally identical $1 / 12$ th scale models of the Authors' specimen 6 were tested to investigate the apparent discrepancy between the full-scale experimental results and the analytical predictions. It was ascertained for the small-scale models that the geometric imperfections, local and overall both, were within the Merrison limits and that the residual stress levels due to welding were similar to those measured in full-scale panel tests. The failure mode of the small panels was identical with the corresponding full-scale specimen. ${ }^{32}$

69. It was found for these tests that if the failure stress $\sigma_{m}$ was compared with the tensile yield stress $\sigma_{y t}$ of the sheet material a high value of $\sigma_{m} / \sigma_{y t}$, close to unity, was obtained. However, to account for the differences between compressive and tensile yield characteristics and the material effects of the welding process the more rational approach was to use as a base value the compressive yield stress $\sigma_{\mathrm{yo}}$ derived from tests on stub panel specimens. The resulting comparison for six nominally identical smallscale panels is shown in Table 6.

70. It is evident that the results have an average value approximately $10 \%$ lower than that reported by the Authors for their corresponding full-scale test and are very close to the predictions from the methods in references 9 and 29 . The use of stub panel results ensures that the ratios of $\sigma_{\mathrm{m}} / \sigma_{\mathrm{Yc}}$ reflect the influence on panel failure of such factors as residual stresses, local buckling and geometric imperfections. This then provides a firm foundation for the empirical coefficients in the design analysis.

71. It could be argued that the Authors' use of tensile yield stress conforms with current design office practice. Nevertheless, it is important for research to provide the basis for design methods such that the real governing parameters are understood and investigated. Later, the effects of using tensile yield stress instead of the corresponding compressive yield stress, and also the change of metal characteristics due to welding, can be incorporated in the design method. Thus, the margin of safety of any particular design can be more rationally estimated and future extrapolations of the empirical formulae will be more securely founded.

\section{Dr M. A. Crisfield, Transport and Road Research Laboratory. Crowthorne}

The Authors are to be congratulated on producing a simple method for the design of stiffened steel compression panels that is easy to apply and gives excellent agreement with their experimental results. As the method relies heavily on empirical relationships, it does not provide a theoretical check on the experimental values. Such theoretical confirmation is desirable if the design method is to be safely extrapolated outside the range of the experiments. The Authors' effective width theory ${ }^{2}$ goes some way to providing this confirmation. However, the method includes an approximate loadshortening relationship for the plate that is likely to lead to an overestimation of the collapse load.

73. I have developed a finite element computer program for the large deffexion elasto-plastic analysis of steel plates that has been used to obtain more accurate

\section{Table 6}

\begin{tabular}{c|c|c|c|c|c|c}
\hline Specimen & $\mathrm{A}$ & $\mathrm{B}$ & $\mathrm{C}$ & $\mathrm{D}$ & $\mathrm{E}$ & $\mathrm{F}$ \\
\hline$\sigma_{\mathrm{m}} / \sigma_{\mathrm{yo}}$ & $0.81^{*}$ & $0.76^{*}$ & 0.83 & 0.80 & 0.81 & 0.80 \\
\hline
\end{tabular}

- Reference 32. 


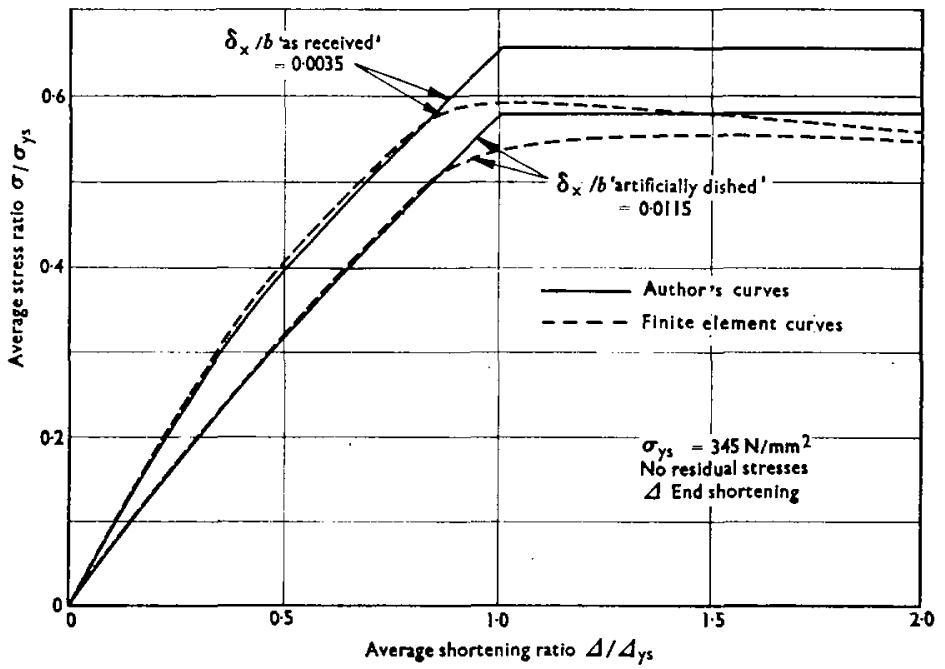

Fig. 10. Comparison of load/shortening relationships for plates with $b / t=70$

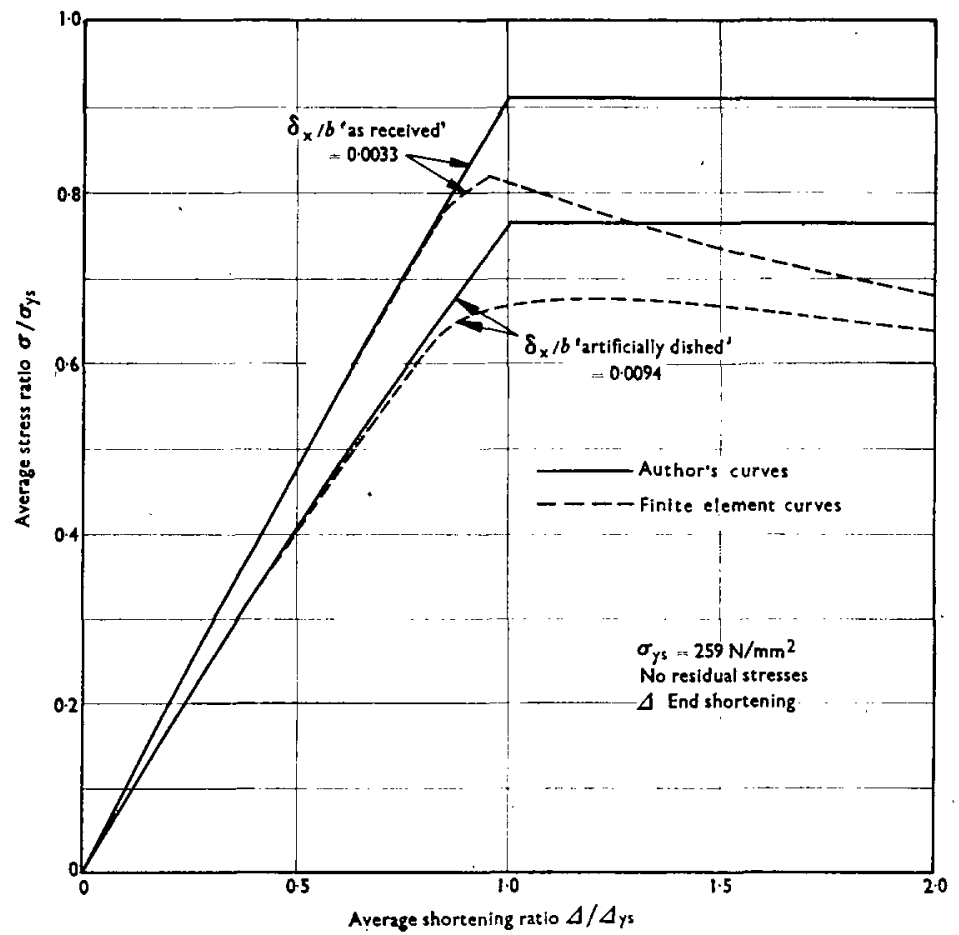

Fig. 11. Comparison of load/shortening relationships for plates with $b / t=47$

Downloaded by [] on [26/04/23]. Copyright (C) ICE Publishing, all rights reserved. 


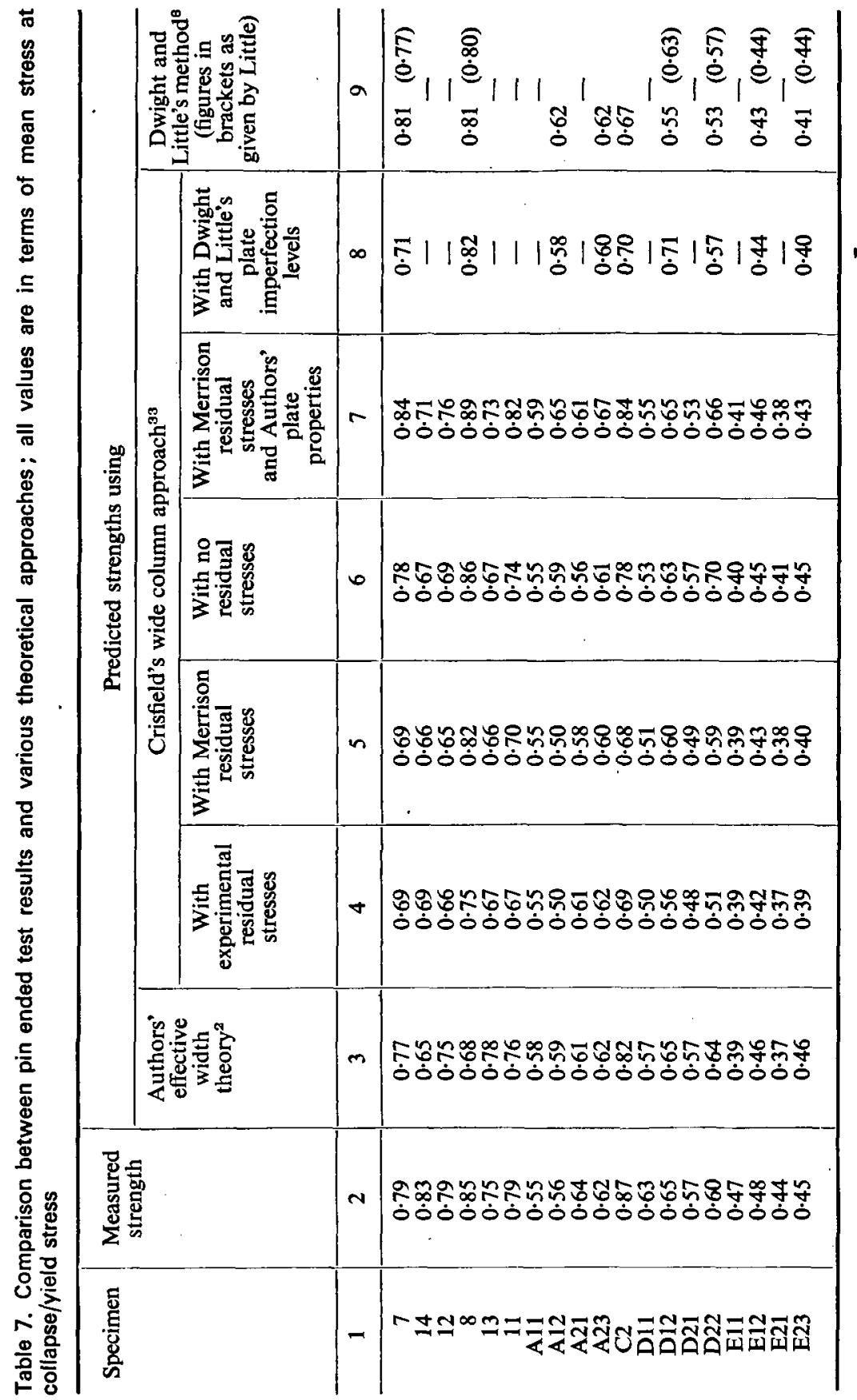


load-shortening curves. ${ }^{33.34}$ The predicted maximum loads have been found to agree well ${ }^{33}$ with box-column results and the unloading curves are in close agreement with a plastic mechanism approach due to Davies. ${ }^{35}$ Figs 10 and 11 compare my loadshortening curves with those used by the Authors in their effective width method. The curves relate to plates with unloaded edges that are constrained to remain straight and with breadth to thickness $(b / t)$ ratios that are averages of those used in the tests conducted by the Authors. The chosen imperfections relate to average as-received and artificially dished specimens. It can be seen that the finite element solutions give lower (about $10 \%$ ) maximum loads. For the more stocky plate with the smaller imperfection, the finite element solution shows a reduction of load as further shortening is applied. This is not allowed for in the Authors' analysis.

74. I have described ${ }^{33}$ a wide column method for the analysis of stiffened plating that has similarities with the Authors' effective width method. However, as I include the finite element plate load-shortening curves, one would expect the method to give significantly lower collapse loads. This is indeed the case (Table 7) and the results are, on average, $8 \%$ lower than those given by the Authors' effective width theory. (The comparison should be made using Merrison levels of residual stress.) My method gives collapse loads that are, on average, $12.5 \%$ lower than the Authors' experimental results.

75. Although there are other differences between the two analysis procedures the most significant difference relates to the plate properties. This has been shown by including the Authors' properties (plate load-shortening relationships) in my wide column analysis. The results are shown in column 7 of Table 7 . There is a very satisfactory correlation between these solutions and those given by the Authors' effective width theory, the latter method giving on average $4 \%$ lower loads.

76. Why does my method, with the more sophisticated plate properties, give worse agreement with the Authors' experimental results? A number of factors could contribute to this discrepancy. Some workers have found that the compressive yield stress is between $5 \%{ }^{36,37}$ and $10 \%{ }^{38}$ higher than the tensile yield stress. (There may also be an increase of strength in the heat affected zone.) The experimental $P / P_{\text {squash }}$ ratios would therefore be lowered and the average error given by my wide column approach would be reduced to 3-8\%. Also, strain hardening has been neglected in my analysis, as has the presence of any upper yield stress. If the latter were present, it could reduce the influence of fibre-yield on the collapse load. For the plates in the as-received condition, the measured imperfections assumedly relate to the maximum amplitudes. Such imperfections are unlikely to lie adjacent to opposite imperfections of comparable severity and consequently their direct inclusion in the analysis would lead to conservative solutions. Little and Dwight ${ }^{37}$ have therefore argued that a mean plate imperfection should be used and suggest a figure of $\Delta_{x}=001 b$. This value is on average one third of the size of the measured imperfection and has been used to compute the results in column 8 of Table 7. In order to compare the results with Dwight and Little's ${ }^{\mathrm{B}}$ solutions, their proposed residual compressive stress levels have also been included $\left(25 \mathrm{~N} / \mathrm{mm}^{2}\right.$ for the intermittently welded and $75 \mathrm{~N} / \mathrm{mm}^{2}$ for the continuously welded specimens). The solutions are generally close (columns 8 and 9 of Table 7) and the average departure from the measured values (as-received specimens only) is reduced to $7 \%$. There is some disagreement between Little (\$49-59) and the Authors concerning the values given by the Divight and Little method. The figures given in brackets in column 9 of Table 7 were supplied by Little; the other figures are taken from column 7 of Table 2.

77. Some doubt must exist concerning the validity of the test results involving large artificially dished imperfections (to about three times the Merrison tolerance). These imperfections were imposed with the aid of a ram and hence significant plastic deformation must have occurred to achieve such a permanent set. This plastic deformation could significantly alter the residual stresses from those assumed in the analysis. One wonders why the Merrison shrinkage forces were used in the analysis when the measured 
residual stresses implied a shrinkage force up to two and a half times larger. ${ }^{\circledR}$ It might be argued that the level of residual stress hardly alters the collapse load. Indeed this is one of the conclusions made by the Authors in an earlier paper. ${ }^{2}$ However, I would argue $^{33}$ that the situation is much more complex. Residual stresses do not have as deleterious an effect as that implied by the Merrison rules. Nonetheless there may be geometries and imperfection levels for which their influence is important. In particular, I consider that they will be important where the $(l / r)$ and $(b / t)$ ratios are each near critical (in the sense that the elastic critical buckling load and squash yield loads coincide). ${ }^{33}$ Also it can be shown theoretically that their influence will be most significant when superimposed on small geometric imperfections. Is the Authors' empirical relationship (equation (4)) able to allow for all these factors? Have the Authors compared their empirical design method with other experimental results?

\section{Mr S. Chatterjee, Bridges Engineering Division, Department of the Environment}

The Authors have used $\Delta_{x}$ to denote the magnitude of the initial imperfection of the flange plate panels and I presume this is meant to be the amplitude of the assumed sinusoidal initial imperfection pattern, i.e. maximum departure from the ideal plane.

79. According to table 23.1 of the Merrison rules, for long plate panels in stiffened flanges, this tolerance $\left[\Delta_{x}\right]$ is applied on the offset over a gauge length $G$ equal to twice the plate panel width, i.e. $G=2 b$. Thus

$$
\begin{aligned}
\delta_{\mathrm{xM}}=\left[\Delta_{\mathrm{x}}\right] & =\frac{G}{30 t}\left(1+\frac{b}{5000}\right)=\frac{b}{15 t}\left(1+\frac{b}{5000}\right) \quad \text { for } t<25 \\
& =\frac{G}{750}\left(1+\frac{b}{5000}\right)=\frac{b}{375}\left(1+\frac{b}{5000}\right) \text { for } t \geqslant 25
\end{aligned}
$$

80. In clause 18.1.2.1 of the Merrison rules, because of the gauge length $G$ being different from the half wavelength of the assumed sinusoidal shape, the effective amplitude has been taken as

$$
\left[\Delta_{x}\right] \frac{b}{G}=\frac{1}{2}\left[\Delta_{x}\right]
$$

for stiffened flanges (the value $\delta_{0}$ recommended to be used in design is $1 \cdot 2$ times this effective value $x$ another factor for likely diversity in several adjacent panels).

81. Thus the fabrication tolerances $\delta_{x}$ and $\delta_{x M}$ used by the Authors appear to be twice the effective value suggested in the Merrison rules.

82. It would appear that equation (4) for $\Delta_{x}$, the following expressions for $\delta_{x M}$ and Figs 5-7 may be unduly onerous for stiffened flanges fabricated to Merrison plate tolerances.

Mr A. T. Ractliffe, School of Marine Technology. University of Newcastle upon Tyne

The Authors have provided useful experimental data in a field where little exists. However, I should like to query the use of the effective width concept in the Perry analysis. In calculating $I^{\prime}$ it is not the secant effective width which is important, but rather the effective tangent modulus of the plating: the so-called reduced effective width. This effect has long been recognized by aeronautical engineers and naval architects. The effective width concept, although apparently simple is the cause of considerable misapprehension among many designers. The tangent effective plate stiffness cannot be obtained directly from the value of the effective width used to calculate plate strength.

Mr J. B. Dwight, University of Cambridge

The current research at Manchester represents the most thorough attack yet on the problem of the stiffened compression panel. The Authors' method is broadly the same 
as that used in BS 449 and BS 153, but has a more sophisticated approach to the plate and column aspects of the problem. Good agreement is shown with their test results to date, although more tests are needed to cover the full range of parameters.

85. The Authors' curves of plate strength in Fig. 2, from which may be read $K_{\text {bs }}$ $\left(=\sigma_{\mathrm{m}} / \sigma_{\mathrm{ys}}\right)$, stem from an elastic analysis with edge yield taken as the criterion of failure. This is an approach adopted by a number of workers. It has the advantage of being not too expensive in computer time, its use being justified at high $b / t$ where elastic buckling is the dominant effect. However, in the practical range (say $b / t=30-60$ ), where inelastic behaviour becomes crucial, there is less justification for it. It is surprising that the Authors, in developing Fig. 2, did not note the results obtained by Moxham ${ }^{17}$ and Crisfield ${ }^{18.33}$ who used realistic elasto-plastic analyses which allowed properly for the effects of residual stresses. (To these must now be added the contribution of Frieze. ${ }^{28}$ )

86. Of particular interest is the detailed manner in which the Authors deal with the plate imperfection (out-of-flatness), taking heed of the Merrison tolerance $\left(\delta_{\mathbf{x}}\right)$. Unfortunately, it is not clear what is meant by 'the measured imperfection' $\left(\delta_{x}\right)$. A designer is presumably intended to take this as $\delta_{\mathrm{xM}}$ or thereabouts, but clarification on this would be helpful. An important feature is that the imperfection assumed is a function of $t$ as well as $b$, with the result that a thick plate comes out relatively stronger than a thin one of the same $b / t$. This seems sensible.

87. The effect of residual stress on the plate strength is allowed for by taking an 'enhanced' imperfection $\left(\Delta_{x}\right)$, as is done for struts in the Perry-Robertson formula. The background to this is not explained, but it appears that the degree of enhancement is

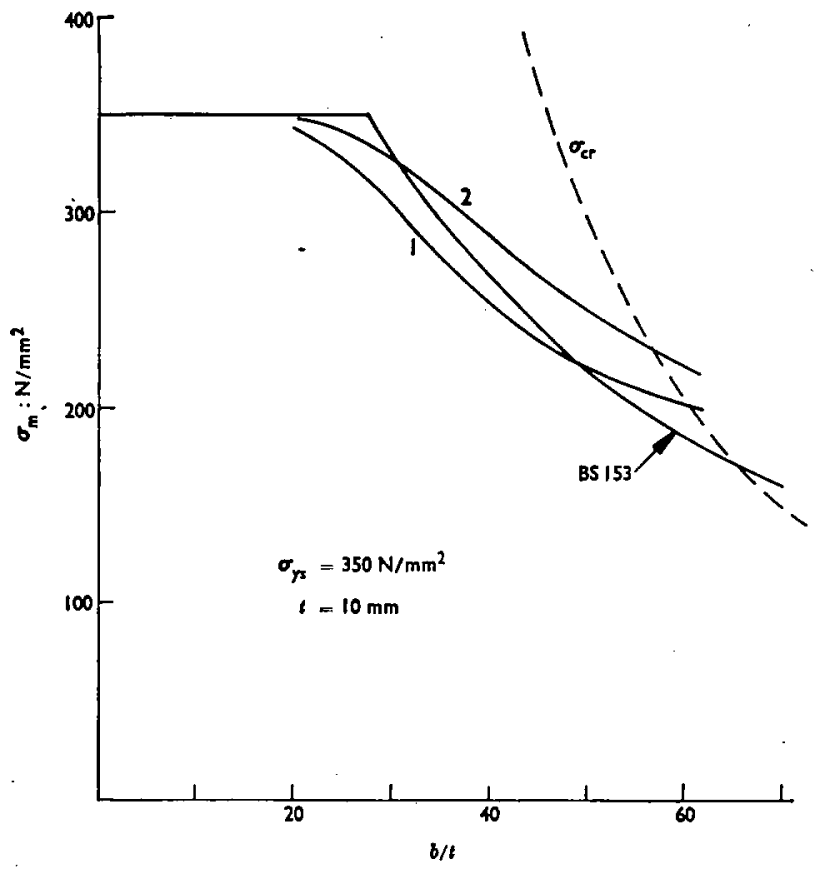

Fig. 12 
independent of the welding parameters. The fact that the level of compressive residual stress may in practice vary by a factor of as much as three to one in plate elements of the same $b / t$, with some consequent variation in strength, is not taken into account. Thus, the plate treatment goes into great detail on imperfections, but seems less precise on residual stress.

88. Figure 2 produces plate strengths which are about right, provided one assumes an imperfection $\delta_{x}$ (before enhancement) of the same order as the Merrison tolerance. This can be seen from Fig. 12 which compares predicted strengths thus obtained (curve 1), taking $\delta_{\mathrm{x}}=\delta_{\mathrm{xM}}$, with those given by BS 153 . The BS 153 values are believed to be sound, being based on tests, and it is seen that curve 1 agrees with them over much of the range, although it tends to get optimistic at high $b / t$.

89. The value of $\delta_{x}\left(=\delta_{x M}\right)$ used in plotting curve 1 is of the order of $b / 140$. This may not at first appear to be unduly large, but when one remembers that it is not the total out-of-flatness that should be taken, but merely the longitudinal 'ripple' component superimposed on the 'hungry horse' bow between stiffeners, a figure of $b / 140$ is surely excessive. Although occasional ripple-type bumps as bad as $b / 200$ are found, these are not accompanied by adjacent sympathetic (i.e. other way) bumps of comparable severity. Thus, the drop in strength they produce will not be as severe as that predicted by the theory, which is based on simply supported edges.

90. A more realistic basis for design should be to take $\delta_{x}=b / 500$, say, or even $b / 1000$, representing the worst degree of equivalent imperfection in a simply supported plate. However, using the Author's procedure with $\delta_{x}=b / 500$ gives results which are clearly too high (curve 2). One is led to the conclusion that the theory used tends to overestimate the strength of a plate, and that to obtain realistic results with it one has to assume an exaggerated value for the actual (pre-enhancement) imperfection.

91. It is true that the theory is based on the pull-in-straight edge condition, which is appropriate to the interior elements in a stiffened flange, whereas the tests leading to the BS 153 rule were pull-in-free (tests on box columns). However, this makes negligible difference in the practical range and only becomes a factor at high $b / t$.

92. Even when the method has been tuned to give realistic results by adjusting $\delta_{x}$, it seems unnecessarily involved to apply. Modern thinking on columns is to equip the designer with three strut curves, covering different classes of section. For plates, it is surely sensible to do likewise and provide two, or at the most three, design curvesinstead of 13 as in Fig. 2. A designer should not be asked to go into the minutiae of plate tolerances. Instead, curve selection should depend primarily on the thickness, thin plates with their inferior flatness and more severe welding stresses being allocated to the low curve; thick plates would be on a higher one. Thin plates could be allowed on to the higher curve, however, when it could be demonstrated that the fabrication procedures would be such as to produce only small residual stresses.

93. In practice, the variation in strength of plates is no greater than it is for columns. The spacing of the two or three design curves would, therefore, be nothing like the total spread of the curves in Fig. 2 (which gives a misleading impression). It would also be convenient if each curve had a cut-off at a definite $b / t$ (as in BS 153), below which the designer would know that he could forget plate buckling. Such curves have been proposed..$^{8}$

94. It would probably lead to cheaper construction if the fabrication tolerance on plate flatness were dispensed with. Evidence suggests that the strength of a welded plate is remarkably insensitive to out-of-flatness, once this exceeds about $b / 500$. Therefore, if the design curves, properly computed, were based on a rather severe level of imperfection, the extra weight of steel would be slight and easily outweighed by the savings in inspection and correction. The whole question of acceptable plate imperfection needs study.

95. The Authors' column treatment assumes a single bay, pin-ended member, with the load applied at the geometric centroid: the same model as covered in their tests. For such a member, it is correct to take account of the discrepancy $e$ between the geo- 

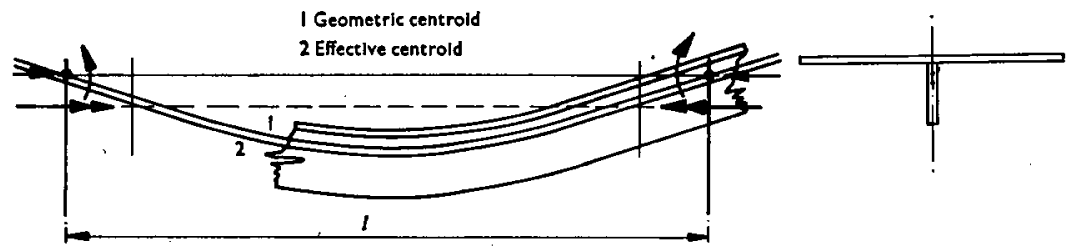

Fig. 13

metric and effective centroids in calculating the effective imperfection (equation (5)), and it is gratifying to see the resulting agreement with tests.

96. However, in practice, stiffened compression panels tend to be continuous over many bays and the situation is different, as has been shown by Little. ${ }^{18}$ Alternate bays buckle up and down. When the plate elements are of high $b / t$, the down-buckling bays receive rotational restraint from the more stable up bays, and the line of action of the applied load adjusts itself so as to pass through the effective centroid at the points of contraflexure in the deformed column, which will be a little way in from either end (Fig. 13). The use of equation (5) in calculating the effective imperfection $\Delta$ is then unduly pessimistic, and it would be more reasonable for design purposes to take $\Delta=\Delta_{\mathbf{s x}}$, still assuming pinned ends.

97. Two modes of collapse need to be considered: plate initiated failure in the down bays and failure initiated by yielding at the stiffener tips in the up bays. The Authors' treatment appears to have been entirely concerned with the former, which is applicable at high $b / t$. When $b / t$ is low, the latter mode becomes critical and presumably it is intended that a separate check should then be made. In so doing, a relatively unfavourable strut curve must be used (high $\alpha$ ) because of the larger extreme fibre distance to the stiffener tip.

98. Apart from these comments, the Authors' column treatment seems rather involved for a design procedure. As with the plate treatment, it is unreasonable to ask a designer to consider imperfections in detail, and surely it would have been better to have employed the European column curves $(\alpha \simeq 0.0020,0.0035,0.0055)$ which will come into use, rather than provide a family of design curves for each steel (Figs 5-7). The Authors' procedure suggests a degree of precision of knowledge which does not yet exist.

99. Two simple design methods are available for interacting local and overall buckling effects in columns. In the effective width method local buckling is catered for by removal of the central part of any non-compact plate elements, the amount removed being purely a function of $b / t$. The remaining (effective) section is then analysed as a column in the usual way. This is the well-known treatment of BS 449 and BS 153, which the Authors have retained.

100. The essence of the other procedure - the fictitious yield method-is to sum up the strengths of the various elements, taking local buckling into effect where necessary, and thus obtain a stub column collapse stress $\sigma_{\text {mav }}$. The full member is then treated as a column composed of a material of yield $\sigma_{\text {mav }}$. This method has been in the UK and US light-gauge codes for many years, but few heavy-gauge designers have met it.

101. The two methods are equally simple to apply. The designer is provided with a formula or chart from which he can obtain the required data for plate elements, depending on their $b / t:$ in one case the effective width, in the other the plate strength $\sigma_{\mathrm{m}}$. He then works out either the effective section properties or else the stub column strength $\sigma_{\text {mav }}$. Then he reads off the column strength from an appropriate column curve, in the one case taking a reduced section with a strut curve based on the full yield $\sigma_{\mathbf{y s}}$, and in the other the full section but with a curve based on a reduced yield $\sigma_{\mathrm{mav}}$.

102. The two methods will give identical results at low $L / r$, assuming they are based on the same plate data, but at high $L / r$ the effective width method in its simple form 


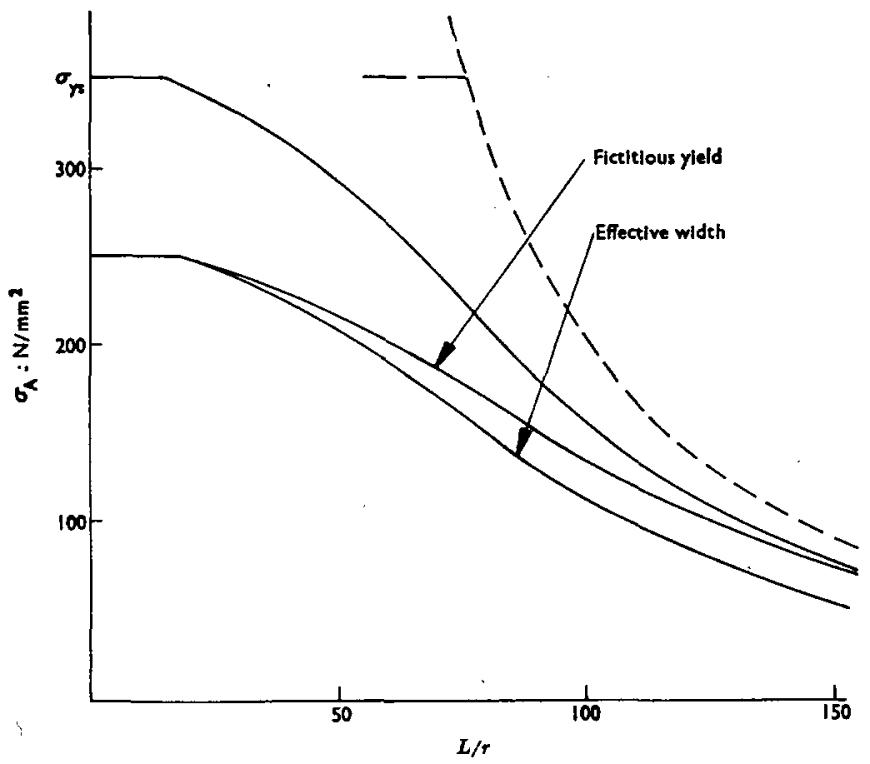

Fig. 14

suffers from an inherent weakness in that it predicts the same proportionate drop in strength due to local buckling as it does at low $L / r$ (Fig. 14). This is clearly wrong because at high $L / r$ the effect of local buckling will be negligible, column buckling being the dominant factor. This defect could be overcome by introducing effective widths which vary with stress, but this would involve an iterative form of calculation which might be unacceptable. The fictitious yield method does not suffer from this weakness and can readily be tailored to suit research results. ${ }^{8}$

\section{Professor Horne and Dr Narayanen}

Mr Allen proposes a general interaction formula which appears to give conservative predictions for all long specimens or specimens with high $b / t$. The method as applied to tests conducted at Monash University ${ }^{13}$ also gives conservative predictions. The main objection to the procedure would seem to be that it does not offer an explicit means for making allowance for various levels of imperfection and the varying ways in which applied and overall imperfections may interact. Like all purely empirical methods it would seem to require direct verification over a large range of parameters before it can be generally accepted.

104. The yield stresses of the plate and stiffener materials for the tests discussed in the Paper are given in references 6, 7 and 39.

105. Mr Davies and Dr Walker ask at what level of negative column imperfection it is possible for the stiffener tripping mode of failure to be induced. This necessarily varies with a number of parameters of which the most important is the $b / t$ ratio for the plate panels. At high $b / t$ a very high negative column imperfection is required to induce tripping because the early buckling of the plates tends to cause failure in the opposite direction. Since this approximate method was written, which deals only with plate failure, tests have been performed on stiffened panels in which tripping failure was 
induced and these are being used in the derivation of an approximate method dealing with this mode of failure.

106. It is interesting to see the results of the model tests. The difficulty with model tests is the problem of inducing completely realistically the effect of welding on a small scale. This can affect the relative yield stresses in the heat affected zone compared with the rest of the material and the levels of distortion induced by welding as well as the absolute level of residual stress, and it requires a careful investigation to ensure that the model panels are reproducing all the characteristics of the full scale. Although model tests are invaluable for comparative investigations of the various parameters, we think the absolute prediction of failure loads need to be correlated with large-scale tests. This is particularly so when the effects of various types of welding detail are under consideration.

107. The writers suggest that tests on stub panel specimens overcome the problems associated with the variability of yield. Previous investigations have indicated that the yield stress in compression for structural steel is indistinguishable from that in tension and it is interesting that this same conclusion was reached by Dorman and Dwight when analysing the results of compression tests on stiffened panels carried out for the Merrison Committee. $^{31}$ It is extremely difficult when testing in compression to eliminate the effect of constraint on the specimen by the interaction between the specimen and the testing platens. In deriving an approximate method it is essential to obtain correlation with the results of tensile tests because these are invariably used as a reference basis of strength. The strength of a stub panel will necessarily depend on the exact length of the stub panel and probably also on the accuracy with which the ends of the specimens are prepared. For these reasons we differ fundamentally from $\mathrm{Mr}$ Davies and $\mathrm{Dr}$ Walker in their preference for correlation with stub panel tests rather than tensile tests.

108. Mr Chatterjee is correct in pointing out the correct interpretation of the quantity $\delta_{X M}$ in equation (4). The value of $\frac{1}{2} \delta_{x M}$ introduced into that equation represents the full imperfection (over a gauge length $b$ ) assumed in the Merrison rules. If the plate panels happen to have an actual imperfection equal to that of the Merrison tolerances, then $\delta_{x}=\frac{1}{2} \delta_{x M}$ in equation (4) so that the total value $\Delta_{x}$ is twice the Merrison imperfection over a gauge length of $b$ when $b / t=30$ and $\sigma_{\mathrm{yg}}=245 \mathrm{~N} / \mathrm{mm}^{2}$. It should be recognized that equation (4) is simply being used as an empirical equation and $\Delta_{x}$ is not intended to represent a directly measurable physical quantity.

109. Dr Crisfield presents some most interesting results derived from a more accurate analysis of the stiffened panels than was applied in our approximate method. He rightly points out that equations (2) and (3) overestimate the strength of an isolated plate panel. It was recognized in formulating the approximate method that the criterion of membrane stress equal to yield stress on the edge of the panel as representing the failure load gave an upper bound solution and the empirical value for $\Delta_{\mathrm{x}}$ given by equation (4) was therefore introduced. It is interesting therefore to modify the imperfections assumed (by Dr Crisfield in testing the validity of the approximate method) as shown in equation (4) before calculating the Authors' curves derived in Figs 10 and 11. The result of so doing is shown in Figs 15 and 16. It will be seen that the approximate load shortening relation is pessimistic in the elastic range but that it gives a reasonable estimate of the ultimate stress at failure.

110. Dr Crisfield's comments about the validity of the test results involving large dished imperfections are fully accepted. It is not imagined that the use of such highly artificial means of inducing imperfections can represent a close quantitative representation of the effects. However, the imperfections induced were very considerable and it is safe to assume that the general trend shown by the induced imperfections is valid. The same can be said for the effect of residual stresses. It would seem likely that residual stresses might have an appreciable effect compared with an almost completely flat and initially completely stress-free stiffened panel. However, the tests did show that the effect of high compared with low residual stresses on the failure load of the complete panel is small. Practical design methods are not concerned with the stiffened panels in 


\section{DISCUSSION}

which residual stresses can be zero or near zero and in the approximate method presented in the Paper it was therefore considered unnecessary to make allowance for the exact level of residual stress.

111. Mr Ractliffe raises the question of the use of the secant effective width of the plating. When one is calculating the extreme fibre stress induced under a given axial force and bending moment on a stiffened panel, the use of the secant effective width is correct. To the extent that in the Perry formula one is adopting the extreme fibre stress as the criterion of failure, the use of the secant effective width is correct. However, when calculating an elastic critical load, the tangent effective width should be used. The Perry-Robertson formula itself is an empirical formula as applied to the calculation of failure loads, and it is impossible to use completely rational arguments to decide whether the secant or tangent effective width should be used in calculating the extreme fibre stress in the Perry formula. In the Merrison rules the tangent modulus was used, this being on the safe side. In deriving the approximate formula in a situation in which an extensive series of tests was available for correlation, it was felt more suitable to use the secant formula. Where the difference between secant and tangent effective width becomes important (for high $b / t$ ) the enhanced value of initial imperfection assumed (equation (4)) ensures the adoption of a safe value for the effective width irrespective of which argument is preferred.

112. Mr Dwight, Dr Little and Mr Bradfield make a number of similar points. Mention is made of the accurate analyses of compressive plate behaviour carried out by Moxham and Crisfield. Moxham's analysis was the main reason for the emphasis on the effect of residual stresses in formulating the Merrison design rules. However, the stiffened panel tests carried out for the Merrison Committee at the Polytechnic of Central London ${ }^{31}$ failed to show any significant effects of high welding residual stresses on failure loads, and one of the main purposes of the extensive series of tests carried out at Manchester was to investigate thoroughly the influence of residual stresses. The

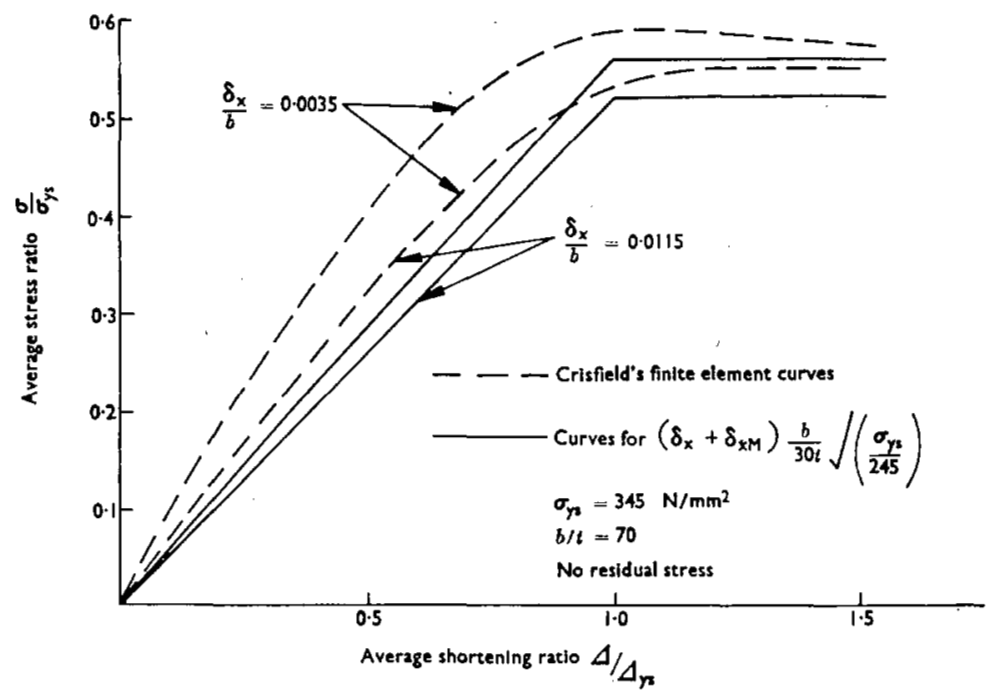

Fig. 15 
Manchester tests have similarly failed to show any reduction of strength due to residual stress, and have led to the approximate methods suggested in the Paper.

113. Both the Moxham and the Crisfield analyses show a considerable effect of residual stress on plate strength in the region $b / t=30-60$ for initial imperfections of the order of $0.001 \mathrm{~b}$. Mr Dwight, Dr Little and $\mathrm{Mr}$ Bradfield all maintain this level of imperfection as typical for stiffened panels in practice. When $t=15 \mathrm{~mm}, \delta_{x}=0 \cdot 001 b$ represents about $40 \%$ of the Merrison recommended tolerances, and we agree that this would be a reasonable effective level to assume for deriving average failure loads. In the Manchester tests carried out on stiffened panels with plate panels in the as-received condition, the effective imperfections (as opposed to the maxima) were of this order. How then is one to account for the failure of the Manchester tests to show any significant effect of residual stress? The explanation must be that the Moxham and Crisfield analyses are based on too idealized boundary and edge loading conditions for the plate panels. The plate panel boundaries are formed by stiffeners and welds on only one side of the plate panel, and low residual stresses can in practice be attained only by welding on one side of the stiffener or by using intermittent welding, or both. The conditions of near idealized boundaries and low residual stress are together impossible to attain, and the benefit of applying refined theories of plate behaviour is less than one might have

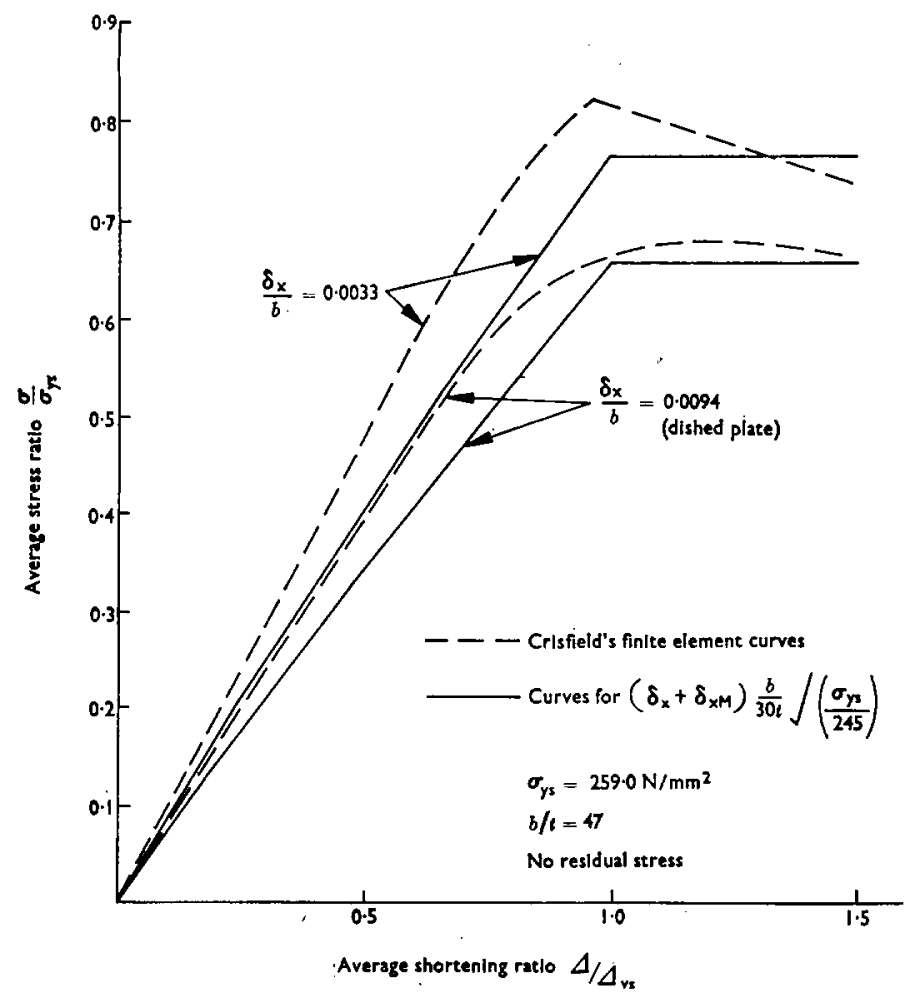

Fig. 16 


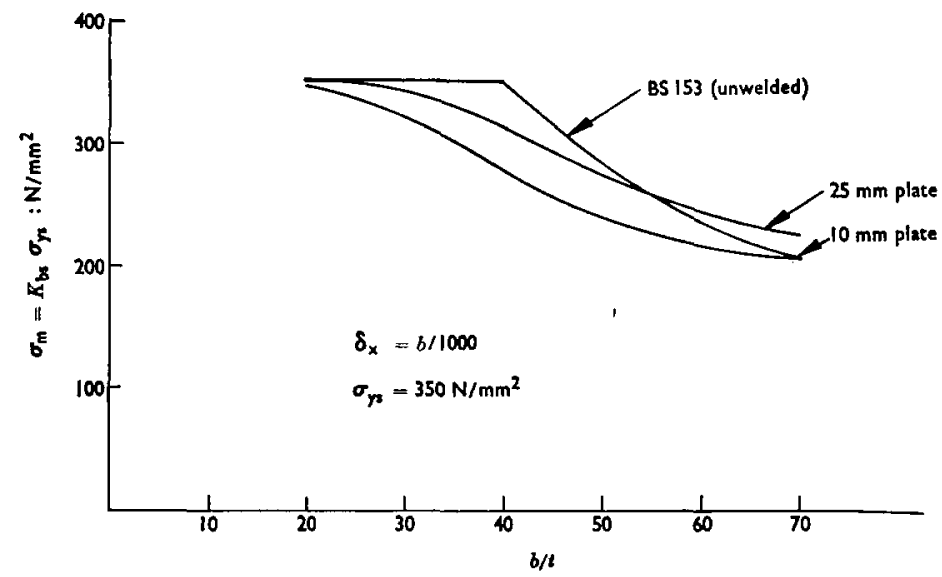

Fig. 17. Comparison of plate strength curves with BS 153

hoped. These considerations led to the adoption of the approximate equations for plate behaviour, these having the advantage of also being expressed in simple algebraic form.

114. The reason for adopting minimum effective imperfections (even when the measured imperfection $\delta_{x}$ is virtually zero) is also now evident. It is necessary to introduce a minimum effective imperfection large enough to allow for the reductions of strength below the value for flat, initially stress-free plate panels caused by practical boundary and initial stress conditions. Mr Bradfield and Dr Little object to the assumption of $\delta_{\mathrm{xM}}$ (and hence $\Delta_{\mathfrak{x}}$ ) being related to $b / t$ rather than $b$ when $t<25 \mathrm{~mm}$, although Mr Dwight regards it as reasonable. There is a tendency for thin plates to possess larger imperfections as measured by $\delta_{\mathbf{x}} / b$, as reflected in the Merrison tolerances, and this should be allowed for. ${ }^{10}$

115. Mr Dwight and Dr Little both refer to the unsafe nature of the approximate estimate of plate strength obtained by the approximate treatment compared with values from BS 153 for welded plates. These criticisms apply only to plates with imperfections that are assumed to be very low in applying the approximate formula and, for the reasons already given, the more appropriate comparison would be with the BS 153 curves for unwelded plates. Fig. 17 shows our proposals for $\delta_{x}=b / 1000, t=25 \mathrm{~mm}$ and $10 \mathrm{~mm}$ in comparison with the BS 153 curve for unwelded plates. They are in reasonable agreement except at high $b / t$ ratios when the BS 153 curves become over-conservative because they refer to plates with longitudinal edges unrestrained in-plane.

116. Dr Little comments on the importance of loss of longitudinal stiffness of the plate panels on the failure loads of stiffened panels. The loss of stiffness due to buckling is allowed for in the approximate method by the effective width concept, and this allowance becomes significant at high $b / t$ values. At low values of $b / t$ the loss of stiffness due to yielding of the initially compressed region of the plate is not allowed for and, as $\mathrm{Dr}$ Little points out, could lead to a reduction of strength of a stiffened panel below that allowed for in the approximate analysis. However, more recently tests ${ }^{41}$ have been carried out on stiffened panels containing plate panels with $b / t=20,30$ and 35 and these have again failed to show a significant reduction of capacity due to high residual stress.

117. We agree that the method as presented is too complicated for design using hand calculation procedures and that the accuracy implied by the close spacing of the curves in Figs 5-7 would be spurious. However, the algebraic expressions are simple 
enough to be programmed on a desk calculator and alternatively could be used to produce design tables once the limits of imperfections to be assumed for design had been decided. These latter should be related to the construction tolerance values and could for the present be made equal to the Merrison tolerances.

118. Mr Dwight and Dr Little both prefer the fictitious yield to the effective width method for the approximate calculation of the strength of stiffened panels. The objection to the fictitious yield approach is precisely that to which Dr Little ascribes great importance, namely the necessity of allowing for reductions of plate stiffness. The fictitious yield method of Dwight and Little uses the full cross-section in calculation of section stiffness properties, and it is not therefore surprising that it overestimates strength at high $b / t$ and low $l / r$ values. In Tables 1 and 2 the only panels to fail by tripping of the stiffeners were specimens 3 and $\mathrm{C} 3$; all the remainder failed because of plate panel failure with or without overall buckling. The fact that the method of Dwight and Little overestimates the strength for some panels with high $b / t$ and low $l / r$ therefore has some significance. In contrast, Mr Dwight claims that the effective width method is incorrect in predicting a drop in strength due to local plate buckling at high values of $l / r$. However, some drop is to be expected. In the presence of plate imperfections, the effective width of a plate panel with high $b / t$ is less than the actual width, even at zero mean stress-a factor not allowed for in the fictitious yield method.

119. In reply to Dr Little about the notation in Tables 1 and $2, \Delta_{x}$ in Table 1 should read $\delta_{x}$; the symbol $r$ in Tables 1 and 2 denotes the radius of gyration of the stiffened panel assuming full width of plate, and therefore differs slightly from that elsewhere in the Paper.

\section{References}

10. Allen D. Buckling interaction-a new design approach. Private communication, 1975.

11. Allen D. Discussion on Local and overall buckling of cold-formed members. J. Struct. Div. Am. Soc. Civ. Engrs, 1975, 101, ST8, Aug., 1719.

12. DE Wolf J. T. et al. Local and overall buckling of cold-formed members. J. Struct. Div. Am. Soc. Civ. Engrs, 1974, 100, ST10, Oct., 2017-2036.

13. Allen D. Correspondence on Analysis and design of stiffened plates for collapse load. Struct. Engr, 1975, 53, No. 9, Sept., 381.

14. Murray N. W. Analysis and design of stiffened plates for collapse load. Struct. Engr, 1975, 53, No. 3, Mar., 153-158.

15. BLEICH F. Buckling strength of metal structures. McGraw-Hill, New York, 1952.

16. LrTtLE G. H. Local and fexural failure in steel compression members. PhD thesis, Cambridge University, 1974.

17. Мохнам К. Е. Theoretical prediction of the strength of welded steel plates in compression. Engineering Department, Cambridge University, 1971, Report CUED/C-Struct/TR 2.

18. CRISFIELD M. A. Large-deflection elasto-plastic buckling analysis of plates using finite elements. Transport and Road Research Laboratory, Crowthorne, 1973, Report LR 593.

19. CRISFIEld M. A. Collapse analysis of box-girder components using finite elements. Symposium on non-linear behaviour and techniques in structural analysis. Transport and Road Research Laboratory, Crowthorne, 1975, Supplementary report $164 \mathrm{UC}$.

20. Davidson H. L. Post-buckling behaviour of long rectangular plates. Fritz Engineering Laboratory, Lehigh University, 1965, Report 248.15.

21. Dawson R. G. and Walker A. C. Post-buckling of geometrically imperfect plates. J. Struct. Div. Am. Soc. Civ. Engrs, 1972, 98, ST1, Jan., 75-94.

22. BRADFIELD C. D. Analysis of measured distortions in steel box-girder bridges. Engineering Department, Cambridge University, 1974, Report CUED/C-Struct/ TR 42. 
23. Dwight J. B. and Mохнам K. E. Welded steel plates in compression. Struct. Engr, 1969, 47, No. 2, Feb., 49-66.

24. Little G. H. and Dwight J. B. Compressive tests on plates with transverse welds. Engineering Department, Cambridge University, 1972, Report CUED/C-Struct/ TR 31.

25. Rogers N. A. The local buckling of welded steel outstands. PhD thesis, Cambridge University, 1975.

26. Mохнам K. E. Further calculations using Moxham's program. Unpublished.

27. CRISFIELD M. A. A computer program to generate load shortening relationships for simply supported steel plates. Transport and Road Research Laboratory, Crowthorne, 1975, Report 683.

28. Frieze P. A. et al. Parametric study on plates in compression. Imperial College of Science and Technology, London, 1975, CESLIC report BG 39.

29. WAlker A. C. and MurRay N. W. Analysis for stiffened plate panel buckling. University of Monash, 1974, Research report 2.

30. Murray N. W. Buckling of stiffened panels loaded axially and in bending. Struct. Engr, 1973, 51, 285-300.

31. Dorman A. P. and Dwight J. B. Tests on stiffened compression panels and plate panels. In Steel box girder bridges. Institution of Civil Engineers, London, $1973,63-75$.

32. Davies P. and WAlker A. C. The use of small scale physical models in structural stability research. Proceedings of the 5th Australasian conference on the mechanics of structures and materials, Melbourne, 1975.

33. Crisfield M. A. Full-range analysis of steel plates and stiffened plating under uniaxial compression. Proc. Instn Civ. Engrs, Part 2, 1975, 59, Dec., 595-624.

34. CRISFIELD M. A. A computer program to generate load/shortening relationship for simply supported steel plates. Transport and Road Research Laboratory, Crowthorne, 1975, Report LR 683.

35. Davies P. PhD thesis, University of London. To be submitted.

36. Sмтrн C. S. Compressive strength of welded steel ship grillages. Paper No. 9, The Royal Institution of Naval Architects, Spring Meetings, 1975.

37. Litrte G. H. and Dwight J. B. Compressive tests on plates with transverse welds. Cambridge University, 1972, Report CUED/C-Struct/TR 31.

38. KamtekAR A. G. et al. Tests on hybrid plate girders. Report 3. Cambridge University, 1974, Report CUED/C-Struct/TR 41.

39. Horne M. R. and Narayanan R. Ultimate capacity of longitudinally stiffened plates used in box girders. Proc. Instn Civ. Engrs, Part 2, 1976, 61, June, 253-280.

40. Flint A. R. and Horne M. R. Conclusions of research programme and summary of parametric studies. In Steel box girder bridges, Institution of Civil Engineers, London, 1973, 173-191.

41. HORNE M. R. et al. The influence of stiffener spacing and weld/gap ratio on the ultimate capacity of axially loaded stiffened plates. Simon Engineering Laboratories, University of Manchester, 1976. 